\title{
Design of an ozone and nitrogen dioxide sensor unit and its long-term operation within a sensor network in the city of Zurich
}

\author{
Michael Mueller ${ }^{1}$, Jonas Meyer ${ }^{2}$, and Christoph Hueglin ${ }^{1}$ \\ ${ }^{1}$ Empa, Swiss Federal Laboratories for Materials Science and Technology, Duebendorf, Switzerland \\ ${ }^{2}$ Decentlab GmbH, Duebendorf, Switzerland \\ Correspondence to: Michael Mueller (michael.mueller@empa.ch)
}

Received: 23 January 2017 - Discussion started: 15 March 2017

Revised: 28 June 2017 - Accepted: 6 July 2017 - Published: 17 October 2017

\begin{abstract}
This study focuses on the investigation and quantification of low-cost sensor performance in application fields such as the extension of traditional air quality monitoring networks or the replacement of diffusion tubes. For this, sensor units consisting of two boxes featuring $\mathrm{NO}_{2}$ and $\mathrm{O}_{3}$ lowcost sensors and wireless data transfer were engineered. The sensor units were initially operated at air quality monitoring sites for 3 months for performance analysis and initial calibration. Afterwards, they were relocated and operated within a sensor network consisting of six locations for more than 1 year. Our analyses show that the employed $\mathrm{O}_{3}$ and $\mathrm{NO}_{2}$ sensors can be accurate to 2-5 and 5-7 ppb, respectively, during the first 3 months of operation. This accuracy, however, could not be maintained during their operation within the sensor network related to changes in sensor behaviour. For most of the $\mathrm{O}_{3}$ sensors a decrease in sensitivity was encountered over time, clearly impacting the data quality. The $\mathrm{NO}_{2}$ low-cost sensors in our configuration exhibited better performance but did not reach the accuracy level of $\mathrm{NO}_{2}$ diffusion tubes $(\sim 2 \mathrm{ppb}$ for uncorrected 14-day average concentrations). Tests in the laboratory revealed that changes in relative humidity can impact the signal of the employed $\mathrm{NO}_{2}$ sensors similarly to changes in ambient $\mathrm{NO}_{2}$ concentration. All the employed low-cost sensors need to be individually calibrated. Best performance of $\mathrm{NO}_{2}$ sensors is achieved when the calibration models also include time-dependent parameters accounting for changes in sensor response over time. Accordingly, an effective procedure for continuous data control and correction is essential for obtaining meaningful data. It is demonstrated that linking the measurements from low-cost sensors to the high-quality measurements from routine air quality monitoring stations is an effective procedure
\end{abstract}

for both tasks provided that time periods can be identified when pollutant concentrations can be accurately predicted at sensor locations.

\section{Introduction}

Numerous gas sensors that are sensitive to ambient concentrations, capable of being integrated in sensor nodes or in measuring devices and available at a low price (USD < 500) have entered the market in recent times. These sensors, in the following referred to as "low-cost sensors", hold the potential for multifaceted applications and therefore attract diverse user groups (Snyder et al., 2013). Measuring devices for air quality monitoring with integrated low-cost sensors are commercially available or form part of scientific activities (e.g. Mead et al., 2013; Li et al., 2012; Piedrahita et al., 2014; Jiao et al., 2017). However, the number of studies demonstrating that low-cost sensors can provide meaningful information on ambient air quality is currently small. This fact points to sensor and/or operational issues that are not yet resolved.

There are numerous studies addressing selected topics related to low-cost sensors: sensors or sensor principles that are utilised in this study are described, e.g. by Williams et al. (2013) (metal oxide $\mathrm{O}_{3}$ sensor) and Stetter and $\mathrm{Li}$ (2008) (amperometric gas sensors). Mead et al. (2013) investigated the behaviour of electrochemical sensors ( $\mathrm{NO}, \mathrm{NO}_{2}$ and $\mathrm{CO}$ ). They showed that they are sensitive to the pbb level, integrated them into a sensor unit and deployed the sensor units within a sensor network in Cambridge, UK, over a 3-month time period. Lin et al. (2015) analysed Aeroqual series 500 $\mathrm{O}_{3}$ and $\mathrm{NO}_{2}$ sensors over 2 months, concluding that they 
have good potential to be useful ambient air monitoring instruments in urban environments provided that they were operated in parallel. Spinelle et al. (2015) investigated the performance of different sensor models determined by field calibrations for a cluster of $\mathrm{O}_{3}$ and $\mathrm{NO}_{2}$ sensors using 5 months worth of data from a semi-rural site. Focusing on sensor operation Miskell et al. (2016) presented an approach to detect drifting sensors within a sensor network based on statistical analysis and data from a small number of reference stations.

Before using air quality sensors, it should be ensured that the sensors are suitable for the intended application. This is, however, not trivial as the technical information provided by manufacturers are often not sufficient and the experience about sensor performance and behaviour under real-world conditions is still limited.

An obvious application of low-cost sensor devices are sensor networks that extend or even replace traditional air pollution monitoring facilities (e.g. diffusion tubes). The lower costs of sensors compared to traditionally employed instruments may result in a higher spatial resolution of sensor networks. Requirements for this application include the sensor network providing additional information compared to existing facilities and the costs of operation and the information gain being balanced.

In this paper we present a case study of this application conducted in the city of Zurich. We engineered a $\mathrm{NO}_{2} / \mathrm{O}_{3}$ sensor node, performed sensor calibration and deployed six sensor units to form a small sensor network in Zurich. Our interest particularly focuses on the achievable performance of the sensor unit, its variation with time and procedures for monitoring the performance of sensors within a sensor network. Moreover, the study aims for the identification of factors that limit the sensor performance and areas of improvement.

\section{Established and existing infrastructure for sensor performance tests in Zurich}

\subsection{Network of sensor units}

We established a small sensor network consisting of six locations in the city of Zurich on 10 June 2015 (Fig. S1 in the Supplement). The developed sensor units (see Sect. 3) were deployed and operated at these locations until 2 August 2016. The criteria for location selection were coverage of different pollution situations, correspondence to a routine air quality monitoring site in terms of the pollution situation (Table 1) and access to a power supply. The sensors were mounted on utility poles, on a metal fence (both at $\sim 3 \mathrm{~m}$ height) or on the railing on the flat roof of a building.

\subsection{Routine air quality monitoring sites in Zurich}

\subsubsection{Site description}

The municipal (Office for environment and health protection, UGZ, City of Zurich) and federal (Swiss Federal Office for the Environment, FOEN) authorities operate six air quality monitoring (AQM) sites for regulatory purposes in the city of Zurich (Fig. S1 in the Supplement). These sites are representative of pollutant situations encountered in the urban background (two sites; site HEU is located in a residential area on a hillside about $200 \mathrm{~m}$ above the city), at urban roadsides (three sites) and on a motorway (one site; see Table 1 for details). The monitoring programme comprises $\mathrm{NO}_{2}$ and $\mathrm{O}_{3}$, among other species, at all sites. Temperature and relative humidity are measured at all sites except at HEU and SWD. We have access to the $1 \mathrm{~min}$ data set for the period January 2015 to August 2016. The data set is complete except for minor data gaps related to calibration periods, instrument maintenance and equipment failures ( $>96.4 \%$ of data at each particular station in the year 2015). Note that the site SWD (located on a motorway) was replaced by an AQM site located in the urban background in January 2016.

\subsubsection{Measured $\mathrm{NO}_{2}$ and $\mathrm{O}_{3}$ concentrations}

Pollutant levels in Zurich are moderate (Table 1) as the economy is dominated by services and there is no heavy industry. Motorised traffic is the main emission source of $\mathrm{NO}_{x}$, accounting for $47 \%$ of the emissions in Zurich (Brunner and Scheller, 2014).

We analysed the 2015 data set in order to find temporal and location-based patterns where sensor measurements from a location of the sensor network can be linked to measurements from AQM sites. Such a link may facilitate the detection of defective sensors or even the improvement of their performance by updating their calibration parameters. The locations of the sensor network are at some distance from AQM sites. Hence, the pollutant concentrations measured by the sensors cannot be assumed to be equal to that of an AQM site throughout.

Computing the differences in $\mathrm{NO}_{2}$ and $\mathrm{O}_{3}$ concentrations with respect to the urban background site ZUE reveals that time periods exist when the concentration differences are usually small in the city of Zurich (see Figs. S3 and S4 in the Supplement). This is related to temporal patterns in source activity (e.g. traffic) and meteorology. Measurements from sites in the city (roadside and background) show that $\mathrm{NO}_{2}$ and $\mathrm{O}_{3}$ concentrations are most homogeneous early in the morning (01:00-03:00 LT). In contrast, the difference between $\mathrm{NO}_{2}$ and $\mathrm{O}_{3}$ concentrations for HEU and ZUE exhibits a different diurnal pattern. Site ZUE is a background site in the city centre whereas site $\mathrm{HEU}$ is located in a suburban area elevated by $200 \mathrm{~m}$. Here, $\mathrm{NO}_{2}$ and $\mathrm{O}_{3}$ concentrations are most similar in the afternoon (11:00-17:00 LT) when the 
Table 1. List of the air quality monitoring (AQM) sites and the sensor network sites. $\overline{\mathrm{NO}_{2}}$ and $\overline{\mathrm{O}_{3}}$ denote the $\mathrm{NO}_{2}$ and $\mathrm{O}_{3}$ annual mean concentrations in 2015 , respectively. $d_{\mathrm{AQM}}$ denotes the distance of the sensor network location to the next AQM site, $d_{\mathrm{ZUE}}$ denotes the distance to the AQM site ZUE. AQM sites in Zurich are operated by the Environment and Health Protection Department (UGZ, City of Zurich) and the Federal Office for the Environment (FOEN). A map of the AQM sites and the sensor network is included in the Supplement.

\begin{tabular}{|c|c|c|c|c|c|c|c|}
\hline Name & Network & $\begin{array}{r}\text { Elevation } \\
\text { [m a.s.1.] }\end{array}$ & Pollutant situation & Location & Group & $\begin{array}{l}\overline{\mathrm{NO}_{2}} \\
{[\mathrm{ppb}]}\end{array}$ & $\begin{array}{r}\overline{\mathrm{O}_{3}} \\
{[\mathrm{ppb}]}\end{array}$ \\
\hline HEU & AQM (UGZ) & 610 & urban background & elevated, hillside & background & 9.4 & 28.5 \\
\hline RGS & AQM (UGZ) & 433 & urban roadside & city & city & 26.2 & 17.6 \\
\hline $\mathrm{SCH}$ & AQM (UGZ) & 415 & urban roadside & city & city & 23.3 & 20.5 \\
\hline STA & AQM (UGZ) & 445 & urban roadside & city & city & 17.5 & 22.4 \\
\hline $\mathrm{SWD}^{1}$ & AQM (UGZ) & 430 & motorway & city & & 24.4 & 18.8 \\
\hline \multirow[t]{2}{*}{ ZUE } & AQM (FOEN) & 408 & urban background & city & background / city & 16.2 & 24.0 \\
\hline & & & & & & $\begin{array}{r}d_{\mathrm{AQM}} \\
{[\mathrm{km}]}\end{array}$ & $\begin{array}{c}d_{\text {ZUE }} \\
{[\mathrm{km}]}\end{array}$ \\
\hline BUE & EMPA & 408 & urban roadside & city & city & 1.4 & 1.4 \\
\hline ETH & EMPA & 535 & urban background & elevated, hillside & background & 1.8 & 3.6 \\
\hline GES & EMPA & 408 & urban roadside & city & city & 0.5 & 0.5 \\
\hline PFI & EMPA & 402 & urban roadside & city & city & 1.6 & 2.4 \\
\hline STB & EMPA & 409 & urban background & city & background & 3.7 & 4.0 \\
\hline WIN & EMPA & 488 & urban roadside & city & city & 0.6 & 1.6 \\
\hline
\end{tabular}

* SWD was replaced by an AQM site located in the urban background in January 2016.

boundary layer is high and well mixed. Average $\mathrm{NO}_{2}$ concentration encountered at site $\mathrm{HEU}$ is slightly lower than at site ZUE. The sum of $\mathrm{NO}_{2}$ and $\mathrm{O}_{3}$ concentration is most homogeneous in Zurich, providing an additional constraint for multi-sensor units. Consequently, $\mathrm{NO}_{2}$ and $\mathrm{O}_{3}$ readings of a sensor located anywhere in Zurich can be expected to be similar to those of the background site ZUE on average in specific time periods, depending on site characteristics.

The use of a background site such as ZUE as reference for the monitoring of low-cost sensor performance is more suitable than using a traffic site. The background site is usually less impacted by local emissions and concentrations are less variable in time.

The AQM sites in Zurich provide comprehensive information about the instantaneous $\mathrm{O}_{3}$ and $\mathrm{NO}_{2}$ concentration field. $\mathrm{O}_{3}$ and $\mathrm{NO}_{2}$ estimates for any location in Zurich derived from the measurements of the most similar AQM site in terms of traffic impact and elevation are probably better than $10 \mathrm{ppb}$ on average (compare Figs. S3 and S4 in the Supplement). That implies that the accuracy of an additional sensor must be better than this value in order to substantially extend the information about $\mathrm{NO}_{2}$ and $\mathrm{O}_{3}$ concentrations in Zurich.

\section{3 $\mathrm{NO}_{2}$ diffusion tube measurements}

The UGZ conducts $\mathrm{NO}_{2}$ diffusion tube measurement campaigns for air quality monitoring in Zurich in varying deployments every year. The diffusion tubes (Palmes et al., 1976) are exposed for 14-day periods and then analysed in the laboratory. The resulting concentrations are usually aggregated to an annual mean value, which includes a correction term.
The UGZ performs diffusion tube measurements at the locations of the AQM sites permanently and at the locations of the sensor network (see Sect. 2.1) in the period 21 July 2015 to 2 August 2016. Diffusion tube measurements provide an accurate $(\sim 2 \mathrm{ppb}$ for uncorrected 14-day average concentrations) and independent reference for the $\mathrm{NO}_{2}$ sensors in terms of biases of the fortnightly mean.

\section{Developed sensor unit}

\subsection{Design}

The sensor units (SUs) consist of two boxes (Fig. 1). Two metal oxide semiconductor-based ozone sensors (Aeroqual SM50 OZU) and a GSM module for data transmission are placed in the first box. Three electrochemical $\mathrm{NO}_{2}$ sensors (Alphasense NO2-B42F) and a temperature and humidity sensor (Sensirion SHT21) are placed in the second box. The NO2-B42F sensors have an ozone detaining membrane (> $500 \mathrm{ppm} \mathrm{h}$ at $2 \mathrm{ppm}$, Alphasense Ltd. (2016); $\sim 1.5-2.5$ years of operation for $23-38 \mathrm{ppb}$ mean $\mathrm{O}_{3}$ concentration). Only the second box is equipped with a ventilator as the $\mathrm{O}_{3}$ sensors have an active fan. The boxes intercommunicate over a radio link. The redundant design of the boxes with respect to the low-cost sensors yields a constellation in which measurements of two $\mathrm{O}_{3}$ and three $\mathrm{NO}_{2}$ sensors can directly be compared with each other. Because it is focused on sensor testing, this is valuable information, especially when the sensor units operate at a distance to the reference AQM sites.

Indeed, one single sensor unit (SU006) is equipped with Alphasense NO2-B4 sensors (predecessor of NO2-B42F). In 


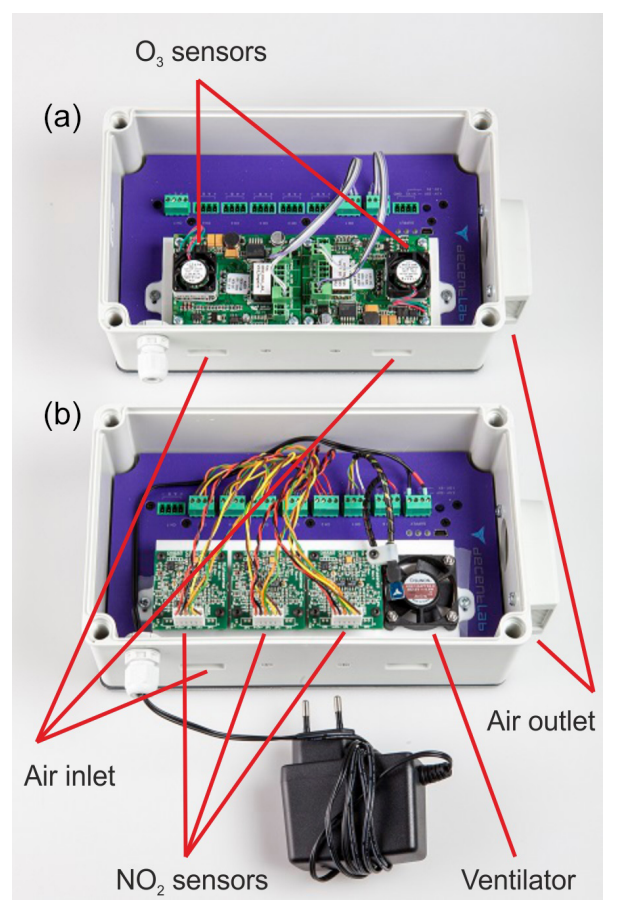

Figure 1. Interior view of the engineered sensor unit: (a) box 1, (b) box 2 .

contrast to the NO2-B42F sensors, these are cross-sensitive to ozone.

The measuring cycle of the $\mathrm{O}_{3}$ sensors lasts approximately $1 \mathrm{~min}$. The sensors are prompted every minute and report the latest available measurement. The $\mathrm{NO}_{2}$ sensors are activated sequentially for $3 \mathrm{~s}$ periods. Measurements are taken every $20 \mathrm{~s}$ and averaged to minute values. The resulting $1 \mathrm{~min}$ measurements are transmitted to and stored in a central database.

The $\mathrm{O}_{3}$ and $\mathrm{NO}_{2}$ raw data exhibit occasionally large positive or negative values that are not related to ambient gas concentrations. These spikes most likely arise from interferences between the transmitting GSM modem and the gas sensors. Their occurrences depend on the actual location of the sensor unit and thereby on the distance and operation mode of the GSM base station that the GSM modem is communicating with. These issues were reduced by increasing the data transmission interval from 1 to $12 \mathrm{~min}$ in the course of the deployment.

The data from each individual sensor in an $\mathrm{SU}$ (two $\mathrm{O}_{3}$ sensors and three $\mathrm{NO}_{2}$ sensors) are treated independently for the data processing as described in Sect. 3.2 and for sensor calibration and evaluation of the sensor model (Sect. 4). However, for comparison of the $\mathrm{NO}_{2}$ sensor measurements with diffusion tubes (Sect. 5.3), reference instruments at AQM sites (Sect. 5.4), and for the calculation of the diurnal cycles of $\mathrm{NO}_{2}$ at the sensor network locations (Sect. 5.6), the mean of the three individual $\mathrm{NO}_{2}$ sensors in the $\mathrm{SU}$ has been used.

\subsection{Data preprocessing}

The $\mathrm{O}_{3}$ and $\mathrm{NO}_{2}$ raw data obtained by the SUs were preprocessed according to the following schema (see Fig. S6 of the Supplement for an illustrative example).

Firstly, all the measurements were forced to the full minute (leaving out the seconds), leading to the omission of a few measurements when there were small variations in measurement frequency. Secondly, measurements that are marked by sensor status flags were removed. Third, we filter the $\mathrm{O}_{3}$ and $\mathrm{NO}_{2}$ raw data in order to remove large outliers (i.e. spikes) from further data analysis. This filter is based on the computations of a local polynomial ( $\mathrm{R}$ function LOESS; R Core Team, 2015) as well as the median absolute deviation (MAD) between measurements and the local polynomial within a moving window of $61 \mathrm{~min}$. We define outliers as measurements deviating more than 10 times the MAD from the local polynomial. If the MAD is smaller than the $25 \%$ quantile of all differences (|local polynomial - measurement|) it is substituted by this value. This prevents the exclusion of measurements during time periods with almost no variation in the pollutant concentration.

In addition, we filter out data from the $\mathrm{NO}_{2}$ sensors that directly follow the switching on of the sensor $(\sim 24 \mathrm{~h})$. Resulting 1 min data completeness of $\mathrm{NO}_{2}$ sensors after preprocessing in the period 11 June 2015 to 2 August 2016 is $>89 \%$ for site ETH and $>96 \%$ for the other sites. One-minute data completeness of $\mathrm{O}_{3}$ sensors is slightly below ( $>82 \%$ ).

\subsection{Sensitivity and selectivity of the $\mathrm{NO}_{2}$ sensors}

We investigated the sensitivity and selectivity of two Alphasense $\mathrm{B} 42 \mathrm{~F} \mathrm{NO}_{2}$ sensors by performing tests in our laboratory. The sensors were integrated in a test device with a similar design to the described SUs during the tests. The sensitivity of the sensors were analysed by exposing them to different concentrations of $\mathrm{NO}_{2}(0,100 \mathrm{ppb}), \mathrm{NO}(0,100 \mathrm{ppb})$, $\mathrm{O}_{3}(0,100 \mathrm{ppb}), \mathrm{CO}(0,1 \mathrm{ppm})$ and $\mathrm{CO}_{2}(0,1000 \mathrm{ppm})$ as well as to relative humidity $(20,80 \%)$ and its rate of change. The gases were added to conditioned zero air. The tests provided information on sensor behaviour in particular situations and revealed limitations of the achievable measurement accuracy in outdoor operation.

Test series were scheduled in order to determine the coefficients $\alpha_{i}$ of Eq. (1).

$$
\begin{aligned}
S_{\mathrm{NO}_{2}} & =\alpha_{0}+\alpha_{\mathrm{NO}_{2}} \cdot \mathrm{NO}_{2}+\alpha_{\mathrm{NO}} \cdot \mathrm{NO}+\alpha_{\mathrm{O}_{3}} \cdot \mathrm{O}_{3}+\alpha_{\mathrm{CO}} \cdot \mathrm{CO} \\
& +\alpha_{\mathrm{CO}_{2}} \cdot \mathrm{CO}_{2}+\alpha_{S_{\mathrm{RH}}} \cdot S_{\mathrm{RH}}+\alpha_{D_{\mathrm{RH}}} \cdot D_{\mathrm{RH}} .
\end{aligned}
$$

$S_{\mathrm{NO}_{2}}$ denotes the sensor signal, $S_{\mathrm{RH}}$ denotes the relative humidity measured by the SUs, $D_{\mathrm{RH}}$ denotes a term representing variations in the signal related to changes in relative humidity, and the other terms denote gas concentrations. Equation (1) has to be solved for $\mathrm{NO}_{2}$ in order to assess the impact of a specific gas on the indicated $\mathrm{NO}_{2}$ concentration. 
Figure 2 depicts three test series. In the first and second series, concentrations of $\mathrm{NO}_{2}(0,70 \mathrm{ppb}), \mathrm{NO}(0,100 \mathrm{ppb}), \mathrm{CO}$ $(0,1 \mathrm{ppm})$ and $\mathrm{CO}_{2}(0,1000 \mathrm{ppm})$ were varied at about $50 \%$ relative humidity. In the third series relative humidity was varied between 40 and $60 \%$ (changes of $5 \%$ every $20 \mathrm{~min}$ ) and $\mathrm{NO}_{2}$ was varied between 0 and $70 \mathrm{ppb}$. The amplitude of the sensor response caused by variations in $\mathrm{RH}$ is of a similar magnitude to the response caused by changes in $\mathrm{NO}_{2}$. Additional test series showed that the signal part caused by a variation in RH depends on the magnitude and the rate of this variation. It exponentially decreases over time, returning to zero. We approximate this signal by the term $D_{\mathrm{RH}}$ in order to enhance the measuring accuracy of the sensor.

$D_{\mathrm{RH}}(t)=\sum_{\Delta t=0}^{-500} \Delta S_{\mathrm{RH}}(t+\Delta t) \cdot \exp \frac{\Delta t}{\Delta t_{0}}$

$\Delta S_{\mathrm{RH}}$ denotes the change in relative humidity, $\Delta t$ denotes the time shift in minutes and $\Delta t_{0}$ is a constant. We decided to determine $\Delta t_{0}$ during field calibration of the sensors as changes in RH might act differently in the field and in the laboratory $\left(\Delta \mathrm{H}_{2} \mathrm{O}, \Delta T\right)$ and the precise physical cause of this signal is unknown to us. Several models were computed with different values for $\Delta t_{0}$ to find the optimal value (see Sect. 4). The term outlined in Eq. (2) mitigates the effect caused by changes in relative humidity but related signal parts can still significantly reduce measurement accuracy over minutes to hours. We kept the relative humidity as constant as possible in test series, focusing on the determination of crosssensitivities.

Our tests of two $\mathrm{NO}_{2} \mathrm{~B} 42 \mathrm{~F}$ sensors did not reveal any cross-sensitivities to gases that would significantly deteriorate the measurement accuracy during ambient measurements (Fig. 2 and Table 2).

\section{Sensor calibration}

Temperature and humidity may both interfere with the $\mathrm{O}_{3}$ and $\mathrm{NO}_{2}$ sensor types integrated in the SUs (manufacturers' specifications). We found that measurements of a sensor can significantly be improved by the determination and application of an individual sensor model. Such a model maps the sensor output to an ambient pollutant concentration taking into account different environmental and pollution conditions. We calibrated the sensors being integrated in the SUs. Accordingly, the sensor model may also incorporate factors specific to the design of the sensor unit (i.e. airflow, temperature variations inside the boxes, electronics).

The effective operation of the sensors in ambient environments requires that the sensor model accurately describes the sensor behaviour for a sufficiently long time period or can be updated while the sensor is in operation. The expression "sufficiently long" depends on the application type and cannot be defined in general.


Figure 2. (a) Time series of sensor signals (NO2_00/NO2_01) $(\mathrm{mV})$, gas concentrations $(\mathrm{ppb})$, temperature $\left({ }^{\circ} \mathrm{C}\right)$ and relative humidity (\%). Time is indicated in days. The gaps between the three parts may last longer than depicted. $\mathrm{CO}$ concentration is scaled by a factor $10, \mathrm{CO}_{2}$ concentration is scaled by a factor 10000 to enhance the clarity of the figure. Note that $\mathrm{O}_{3}$ concentration is constant at $0 \mathrm{ppb}$ in this series. (b) Measured and predicted sensor signal (Eq. 1 with $\alpha_{\mathrm{NO}_{2}} \neq 0, \alpha_{D_{\mathrm{RH}}} \neq 0$ and $\alpha_{i}=0$; mean sensor value subtracted). (c) Histogram of differences between $\mathrm{NO}_{2}$ predictions (Eq. 1 as specified in $\mathbf{b}$, solved for $\mathrm{NO}_{2}$ ) and measurements of the reference instrument.

\subsection{Parallel and remote calibration}

We tested two calibration approaches which differ only with respect to the used input data: the first one (denoted by PAR) utilises only measurements from reference instruments and SUs while the SUs run in parallel with reference instruments of particular air quality monitoring stations (distance 
Table 2. Numeric values of the parameters $\alpha_{i}$ (Eq. 1) of two models derived from data from the three test series depicted in Fig. 2. The parameters $\alpha_{\mathrm{CO}}, \alpha_{\mathrm{CO}_{2}}$ and $\alpha_{\mathrm{NO}}$ were omitted in the first model and estimated in the second model. $r$ denotes the Pearson correlation coefficient and $N$ the number of 1 min measurements used for the parameter estimation. Units for coefficients $\alpha_{i}$ are $\mathrm{mV} \mathrm{ppb}^{-1}$, for RMSE is $\mathrm{mV}$.

\begin{tabular}{|c|c|c|c|c|c|c|c|c|c|}
\hline $\begin{array}{l}\text { Sensor } \\
\left(\mathrm{NO} 2 \_\mathrm{XX}\right)\end{array}$ & const & $\alpha_{\mathrm{NO}_{2}}$ & $\begin{array}{r}\alpha_{D_{\mathrm{RH}}} \\
\left(\Delta t_{0}=120 \mathrm{~d}\right)\end{array}$ & $\alpha_{\mathrm{CO}}$ & $\alpha_{\mathrm{CO}_{2}}$ & $\alpha_{\mathrm{NO}}$ & RMSE & $r$ & $N$ \\
\hline 00 & -15.91 & 0.1593 & 0.70 & - & - & - & 0.93 & 0.98 & 5452 \\
\hline 00 & -15.93 & 0.1606 & 0.70 & $1.21 \times 10^{-4}$ & $1.87 \times 10^{-7}$ & $-1.75 \times 10^{-3}$ & 0.94 & 0.98 & 5235 \\
\hline 01 & -0.09 & 0.1547 & 0.63 & - & - & - & 0.92 & 0.98 & 5136 \\
\hline 01 & -0.13 & 0.1548 & 0.63 & $1.35 \times 10^{-4}$ & $1.81 \times 10^{-7}$ & $-2.04 \times 10^{-4}$ & 0.92 & 0.98 & 4932 \\
\hline
\end{tabular}

between sensor and reference instrument $<5 \mathrm{~m}$ ). Each SU operated for more than 3 months at an AQM site before being moved to a location of the sensor network. The second approach (denoted by PAR/REM) is an extension of the first one. The calibration PAR/REM is based on the combination of two data sets: data obtained when the sensors were operated at one of the AQM sites (same data set as PAR) and data from selected time periods in which the SUs were operated at a distance from the AQM stations at a specific location of the sensor network (REM, distance of 0.5 to $4.0 \mathrm{~km}$ between sensor and reference instrument; see Tables 1 and 3).

Measurements from the background site ZUE were taken as reference values for all the SUs irrespective of their location within the sensor network for the remote calibration (REM). Therefore, time periods had to be identified when the $\mathrm{NO}_{2}$ and $\mathrm{O}_{3}$ concentrations at ZUE and at the particular sensor locations were likely to be similar. This was realised by computing the $30 \mathrm{~min}$ average $\mathrm{NO}_{2}$ and $\mathrm{O}_{3}$ concentration ranges of two dedicated groups of AQM sites. The first group, denoted by "city", contains the AQM sites RGS, SCH, STA and ZUE while the second group, denoted by "background", contains the AQM sites HEU and ZUE (see Table 1 for details). These groups provide plausible estimators for all the locations of the sensor network. We set the threshold for the maximum allowed difference in pollutant concentration within these groups to $5 \mathrm{ppb}$ so that about $10 \%$ of the data are used for sensor calibration (REM) during the operation of the sensor network (see also Fig. S4 in the Supplement). In $90 \%$ of the selected time periods the group's mean $\mathrm{NO}_{2}$ and $\mathrm{O}_{3}$ concentrations, respectively, were in the range (2.7, 22.4) and (1.7, 60.1) ppb (background set) and $(3.6,31.9)$ and $(0.5,35.7) \mathrm{ppb}$ (city set). Except for $\mathrm{O}_{3}$ concentrations within the group background, the span in concentration is limited in the selected time periods. This means that the data selected during the operation of the sensor network provides better constraints for the sensor drift than for the sensitivity.

The measurements from the SUs as well as from the reference instruments were averaged to 5 min mean values before being utilised as model input in both approaches (PAR, PAR/REM). Table 3 summarises the calibration and operation periods of the SUs. The range of pollutant concentrations and of meteorological parameters included in the models is given by the location and the time period in which the SUs ran in parallel to the reference instruments of the AQM sites.

\subsection{Sensor models}

A set of statistical models were evaluated that relate the sensor output under specific meteorological conditions (temperature, humidity) to the ambient gas concentration. Only explanatory variables were included in the sensor models that are directly measured by sensors integrated in the SUs. We analysed two model groups: models from the first group have constant sensitivity (Eqs. 3 and 4). Models of the second group assume that the sensitivity is subject to variations depending on changing meteorological conditions (Eqs. 5 and $6)$.

$$
\begin{aligned}
\mathrm{O}_{3} & =a_{0}+a_{1} \cdot S_{\mathrm{O}_{3}}+a_{2} \cdot S_{T}+a_{3} \cdot S_{T}^{2}+a_{4} \cdot S_{\mathrm{RH}}+\varepsilon_{\mathrm{O}_{3}} \\
\mathrm{NO}_{2} & =b_{0}+b_{1} \cdot S_{\mathrm{NO}_{2}}+b_{2} \cdot S_{T}+b_{3} \cdot S_{\mathrm{RH}}+b_{4} D_{\mathrm{RH}} \\
& +b_{5} \cdot C_{\mathrm{O}_{3}}+\varepsilon_{\mathrm{NO}_{2}} \\
\mathrm{O}_{3} & =\left(m_{0}+m_{1} \cdot S_{\mathrm{O}_{3}}+m_{2} \cdot S_{\mathrm{O}_{3}}^{2}\right) \cdot\left(m_{3}+m_{4} \cdot S_{T}+m_{5} \cdot S_{T}^{2}\right) \\
& +\varepsilon_{\mathrm{O}_{3}} \\
& =c_{0}+c_{1} \cdot S_{\mathrm{O}_{3}}+c_{2} \cdot S_{\mathrm{O}_{3}}^{2}+c_{3} \cdot S_{T}+c_{4} \cdot S_{T}^{2} \\
& +c_{5} \cdot S_{\mathrm{O}_{3}}^{2} \cdot S_{T}+c_{6} \cdot S_{\mathrm{O}_{3}} \cdot S_{T}+c_{7} \cdot S_{\mathrm{O}_{3}} \cdot S_{T}^{2}+\varepsilon_{\mathrm{O}_{3}} \\
\mathrm{NO}_{2} & =\left(n_{0}+n_{1} \cdot S_{\mathrm{NO}_{2}}\right) \cdot\left(n_{2}+n_{3} \cdot S_{T}\right)+n_{4} \cdot D_{\mathrm{RH}} \\
& +n_{5} \cdot \mathrm{O}_{3}+\varepsilon_{\mathrm{NO}_{2}} \\
& =d_{0}+d_{1} \cdot S_{\mathrm{NO}_{2}}+d_{2} \cdot S_{T}+d_{3} \cdot S_{\mathrm{NO}_{2}} \cdot S_{T}+d_{4} \cdot D_{\mathrm{RH}} \\
& +d_{5} \cdot C_{\mathrm{O}_{3}}+\varepsilon_{\mathrm{NO}_{2}}
\end{aligned}
$$

$a_{i}, b_{i}, c_{i}, d_{i}, m_{i}$ and $n_{i}$ denote model coefficients. $S_{\mathrm{O}_{3}}, S_{\mathrm{NO}_{2}}$, $S_{T}$ and $S_{\mathrm{RH}}$ denote $\mathrm{SU}$ sensor readings of $\mathrm{O}_{3}, \mathrm{NO}_{2}$, temperature and relative humidity, respectively. $\mathrm{O}_{3}$ and $\mathrm{NO}_{2}$ denote the readings of the reference instruments. $\varepsilon_{\mathrm{O}_{3}}$ and $\varepsilon_{\mathrm{NO}_{2}}$ denote error terms. $C_{\mathrm{O}_{3}}$ is the ozone concentration provided by applying Eqs. (3) or (5) or given by reference instruments. It is only required for the three NO2-B4 sensors of sensor unit SU006 as they are cross-sensitive to $\mathrm{O}_{3}$.

The terms $b_{0}$ and $d_{0}$ denote either a constant value, a step function or a piecewise linear function. The intervals of these functions refer to the deployment periods of the sensors at 
Table 3. Operation of the sensor units (SU). PAR denotes the calibration of sensors of the SU while they were co-located with instruments from AQM sites, 2nd-PAR denotes the inspection of the sensor performance after operation time (co-location with instruments from AQM sites), and REM denotes the operation of the SUs at a sensor network location. $T_{\mathrm{amb}}, T_{\mathrm{sensor}}, \mathrm{O}_{3}$ and $\mathrm{NO}_{2}$ indicate the range of ambient temperature measured by instruments from the AQM site, temperature inside the SU and ozone and nitrogen dioxide, respectively, during the calibration periods. SU006 is equipped with Alphasense $\mathrm{NO}_{2} \mathrm{~B} 4$ sensors, while the others are equipped with $\mathrm{Alphasense} \mathrm{NO}_{2} \mathrm{~B} 42 \mathrm{~F}$ sensors.

\begin{tabular}{|c|c|c|c|c|c|c|c|c|}
\hline SU ID & Location & $\begin{array}{l}\text { Date } \\
\text { yyyy-mm-dd }\end{array}$ & $\begin{array}{l}\text { Date } \\
\text { yyyy-mm-dd }\end{array}$ & Mode & $\begin{array}{l}T_{\mathrm{amb}} \\
{\left[{ }^{\circ} \mathrm{C}\right]}\end{array}$ & $\begin{array}{r}T_{\text {sensor }} \\
{\left[{ }^{\circ} \mathrm{C}\right]}\end{array}$ & $\begin{array}{r}\mathrm{O}_{3} \\
{[\mathrm{ppb}]}\end{array}$ & $\begin{array}{l}\mathrm{NO}_{2} \\
{[\mathrm{ppb}]}\end{array}$ \\
\hline 1 & RGS & 2015-02-06 & $2015-05-18$ & PAR & $(-5.6,26.7)$ & $(-3.2,30.1)$ & $(2.0,60.4)$ & $(1.7,147.7)$ \\
\hline 1 & BUE & 2015-06-10 & 2016-08-02 & REM & & & & \\
\hline 2 & ZUE & $2015-02-02$ & $2015-04-28$ & PAR & $(-4.7,23.9)$ & $(-5.0,30.1)$ & $(2.0,66.4)$ & $(2.2,61.3)$ \\
\hline 2 & ETH & $2015-04-28$ & 2016-08-02 & REM & & & & \\
\hline 3 & ZUE & 2015-02-02 & $2015-05-19$ & PAR & $(-4.7,27.0)$ & $(-5.1,34.3)$ & $(2.0,84.6)$ & $(1.6,61.3)$ \\
\hline 3 & STB & 2015-06-10 & 2016-08-02 & REM & & & & \\
\hline 4 & RGS & 2015-02-06 & $2015-05-06$ & PAR & $(-5.6,24.7)$ & $(-3.2,32.6)$ & $(2.0,60.4)$ & $(1.7,143.8)$ \\
\hline 4 & PFI & 2015-06-10 & 2016-02-05 & REM & & & & \\
\hline 4 & $\mathrm{SCH}$ & 2016-02-05 & 2016-03-14 & 2nd-PAR & & & & \\
\hline 5 & $\mathrm{SCH}$ & $2015-02-06$ & $2015-05-18$ & PAR & $(-5.1,29.4)$ & $(-4.7,34.1)$ & $(2.0,77.8)$ & $(0.9,85.2)$ \\
\hline 5 & WIN & 2015-06-10 & 2016-08-02 & REM & & & & \\
\hline 6 & $\mathrm{SCH}$ & 2015-02-06 & $2015-05-18$ & PAR & $(-5.1,27.4)$ & $(-4.7,33.0)$ & $(2.0,77.8)$ & $(0.9,85.2)$ \\
\hline 6 & GES & 2015-06-10 & 2016-02-05 & REM & & & & \\
\hline 6 & $\mathrm{SCH}$ & 2016-02-05 & 2016-03-14 & 2nd-PAR & & & & \\
\hline 7 & $\mathrm{SCH}$ & $2015-10-27$ & 2016-02-05 & PAR & $(-5.9,20.3)$ & $(-5.7,21.9)$ & $(2.0,39.4)$ & $(0.3,75.9)$ \\
\hline 7 & PFI & 2016-02-05 & 2016-08-02 & REM & & & & \\
\hline 8 & $\mathrm{SCH}$ & $2015-10-27$ & 2016-02-05 & PAR & $(-5.9,20.3)$ & $(-5.5,22.8)$ & $(2.0,39.4)$ & $(0.3,75.9)$ \\
\hline 8 & GES & 2016-02-05 & 2016-08-02 & REM & & & & \\
\hline
\end{tabular}

different locations or to equally long time periods. The effective length of these time periods can slightly deviate from the target value if the duration of the available data set is not a multiple of the target length. Obviously, when sensors operate within the sensor network, employing a step function or a piecewise linear function is only meaningful if remote calibration (PAR/REM) is applied.

The term $D_{\mathrm{RH}}$ (Eq. 2) was computed based on minute values of $\Delta S_{\mathrm{RH}}$ and then sampled to a 5 min interval to be utilised in the sensor calibration procedure. We excluded $\mathrm{NO}_{2}$ data from the parameter estimation for $30 \mathrm{~min}$ after rapid changes in $\mathrm{RH}\left(\left|\Delta S_{\mathrm{RH}}\right|>1.65 \%\right.$ per $\left.5 \mathrm{~min}\right)$ if the range of $\mathrm{RH}$ exceeds $5 \%$ within these $30 \mathrm{~min}$. Only $\mathrm{O}_{3}$ concentrations larger than $2 \mathrm{ppb}$ were used for the calibration of the $\mathrm{O}_{3}$ sensors.

We neglected any concentration differences between the instruments arising from different sampling frequencies as well as from short spatial distances.

\subsection{Performance of the sensor models}

Each SU has been operated in parallel to instruments of an air quality monitoring site for at least 3 months before being moved to a location within the sensor network (see Table 3 regarding calibration details). Figures $3 \mathrm{a}$ and 4 summarise the performance of different sensor models derived from this data set (calibration CAL). The analysis is intended to reveal those factors the sensors most strongly depend on. Perfor- mance is indicated by means of the root mean square error based on measurements of calibrated sensors and measurements from the AQM sites in a threefold cross-validation. Initial performances of the $\mathrm{O}_{3}$ and $\mathrm{NO}_{2}$ sensors are about 3-5 and 5-7 ppb (5 min mean values; residuals exceeding $50 \mathrm{ppb}$ (single values) are considered gross outliers; negative $\mathrm{O}_{3}$ values are set to zero for RMSE computation). The $\mathrm{O}_{3}$ sensors clearly outperform the $\mathrm{NO}_{2}$ sensors in this stage. The scatter in the results for one individual model can be related to unequally performing sensors and to different locations (i.e. pollutant conditions) and data periods (i.e. data partitioning during cross-validation). This shows that test procedures are required that cover a wide range of expected operation conditions.

The performance of $\mathrm{NO}_{2}$ sensor models based on data from when the SUs ran in parallel to instruments from AQM sites as well as when they operate remotely from AQM sites within the sensor network (calibration PAR/REM) is depicted in Fig. 3b. For some of the models shown in Fig. 3 the terms $b_{0}$ and $d_{0}$ are time dependent. The better performance of models with $b_{0} \neq$ const and $d_{0} \neq$ const compared to models with $b_{0}=$ const and $d_{0}=$ const suggests that the $\mathrm{NO}_{2}$ sensor behaviour slightly varies over time. Piecewise linear functions referring to 60-day intervals exhibit good performance.

The application of a term that compensates effects due to changes in relative humidity improves the performance of the $\mathrm{NO}_{2} \mathrm{~B} 42 \mathrm{~F}$ sensor models. This corroborates the impact of 

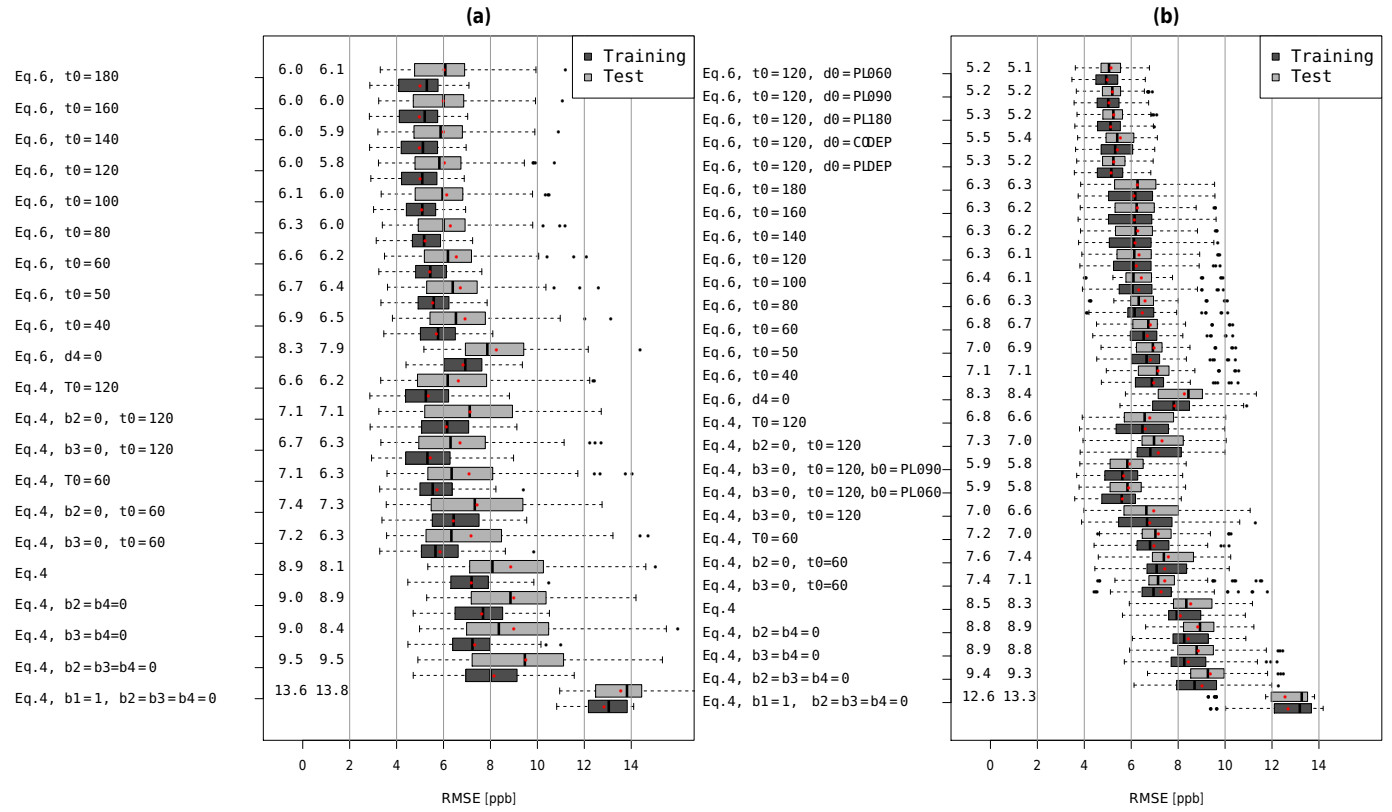

Figure 3. Performance of $\mathrm{NO}_{2}$ sensor models based on Eqs. (4) and (6). (a) Model parameters estimated based on data when the SUs ran in parallel with instruments of AQM sites (PAR). The threefold cross-validation utilises the first, second and third parts of the data as test data while the remaining data are part of the training data set (threefold cross-validation, three permutations). (b) Model parameters estimated based on data from when the SUs ran in parallel with instruments of AQM sites and remote (PAR/REM). Data from every third day are part of the training data set, data from the remaining days are part of the test data set (threefold cross-validation, three permutations). Only $\mathrm{NO}_{2}$ B42F sensors were included in (a, b). The terms PLX, PLDEP and CODEP refer to the parameters $b_{0}$ and $d_{0}$ in Eqs. (4) and (6). $b_{0}$ and $d_{0}$ are constants if not specified. PLX denotes a piecewise linear function with an interval length of about $X$ days, PLDEP denotes a piecewise linear function with the intervals being equal to the deployment periods and CODEP denotes a stepwise function with the intervals being equal to the deployment periods. T0 refers to the parameter $\Delta t_{0}$ in Eq. (2). The two numbers indicated for each model refer to the mean (red dot) and the median root mean square error (RMSE).

relative humidity changes on the sensor signal observed in our laboratory. The parameter $\Delta t_{0}$ for the description of the memory effect of changes in relative humidity equals about $120 \mathrm{~min}$ for best performing models. Moreover, a small dependency of temperature on the sensitivity of the sensor is likely, as models described by Eq. (6) slightly outperform models described by Eq. (4).

Similar results were obtained for the models applied to the three $\mathrm{NO}_{2}$ B4 sensors in SU006. However, these models include a linear ozone correction term (Eqs. 4 and 6). This term is based on measurements from the reference instrument as they are more accurate than those from the integrated $\mathrm{O}_{3}$ sensors.

The analysis of the $\mathrm{O}_{3}$ sensor data, obtained in the time period in which the SUs were operated at AQM sites, lets the sensor signal appear to be significantly, non-linearly temperature dependent. However, the relation between the sensor output and the ambient $\mathrm{O}_{3}$ concentration turned out to be not stable over time. The sensitivity of the $\mathrm{O}_{3}$ sensors of all SUs has progressively decreased since the start of the field deployment. This behaviour is more pronounced for SUs operating at roadside locations (Fig. 5). A decrease in the sensitivity clearly became evident for the $\mathrm{O}_{3}$ sensors of SU007 and SU008 during the lasting calibration of about 3-months. Thus, the $\mathrm{O}_{3}$ sensors of SU007 and SU008 were excluded from the assessment of the sensor models. The reason is unclear but might be related to ambient particulate matter impairing the sensors by blocking the mesh (sensor manufacturer, personal communication). For SUs 1-6 the sensor deterioration could have been initiated as well during the calibration phase. If so, the estimated parameters of the calibration models would be influenced by this process. It is likely that the decrease in sensitivity is partly compensated by the temperature dependency.

The models that perform best are summarised in Table 4 under DS 3.

\section{Achieved long-term sensor performance}

\subsection{Sets of processed sensor data}

We produced three data sets based on different sensor models in order to investigate in detail the long-term sensor performance achieved during the operation of the sensor network (11 July 2015-2 August 2016). Data set 1 (DS 1) utilises a simple linear regression as the sensor model (Eqs. 3 and 4 
Table 4. Description of the computed data sets. $f_{\mathrm{O}_{3}} \sim t$ and $f_{\mathrm{NO}_{2}} \sim t$ denote wether the model is time dependent. The descriptors PAR and REM denote whether the parameters of the sensor model are determined based on data from co-location periods or also from data during sensor network operation.

\begin{tabular}{llllll}
\hline Data set & $\mathrm{O}_{3}$ model & $f_{\mathrm{O}_{3}} \sim t$ & $\mathrm{NO}_{2}$ model & $f_{\mathrm{NO}_{2}} \sim t$ & Calibration data \\
\hline 1 & Eq. (3): $a_{2}=a_{3}=a_{4}=0$ & no & Eq. (4): $b_{2}=b_{3}=b_{4}=0$ & no & PAR \\
2 & Eq. (5): $c_{0}=$ const, $c_{2}=c_{5}=0$ & no & Eq. (6): $d_{0}=$ const, $\Delta t_{0}=120$ min & no & PAR \\
3 & Eq. (5): $c_{0}=$ const, $c_{2}=c_{5}=0$ & no & $\begin{array}{l}\text { Eq. (6): } d_{0}: \text { piecewise linear function } \\
\text { (interval length of } 60 \text { days), } \Delta t_{0}=120 \text { min }\end{array}$ & yes & PAR/REM \\
& & & (ing) & \\
\hline
\end{tabular}

EQ. 5

EQ. $5, c 4=c 7=0$

EQ. $5, \mathrm{c} 2=\mathrm{c} 5=0$

EQ. $5, c 2=c 4=c 5=c 6=c 7=0$

EQ. $3, \quad a 2=a 3=0$

EQ. $3, \quad a 2=a 4=0$

EQ. $3, a 4=0$

EQ. $3, \quad a 3=0$

EQ. $3, \quad a 3=a 4=0$

EQ. $3, a 2=a 3=a 4=0$

EQ. $3, \quad a 1=1, \quad a 2=a 3=a 4=0$

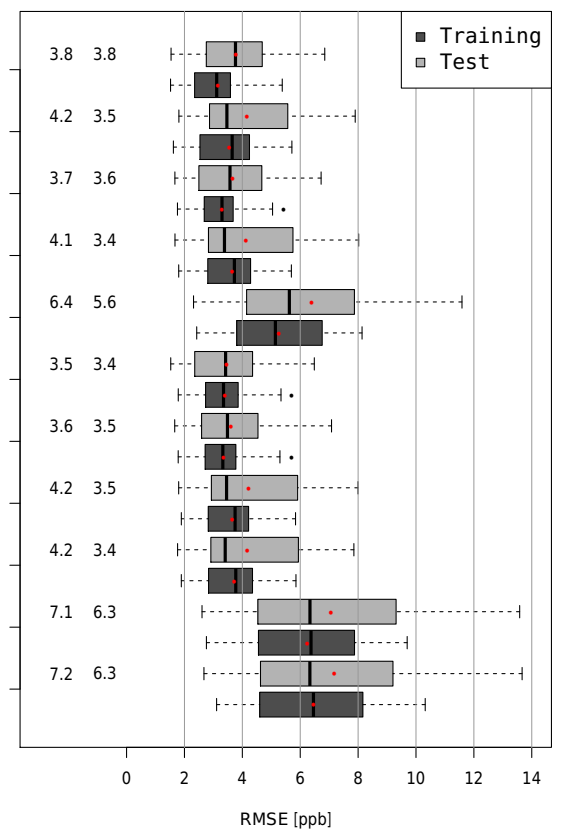

Figure 4. Results for the $\mathrm{O}_{3}$ sensors analogue to Fig. 3a. Negative $\mathrm{O}_{3}$ values set to zero for RMSE computation.

with only $a_{0}, a_{1}, b_{0}$ and $b_{1}$ different from 0 ). Its parameters were determined when the operated sensors were co-located with instruments at AQM sites (calibration PAR). Data sets 2 and 3 (DS 2, DS 3) are based on sensor models given by Eqs. (5) and (6). The parameters of the sensor models utilised for DS 2 were determined based on data from when the SU were at the AQM sites (calibration PAR), the parameters of the sensor models utilised in DS 3 were determined based on data from calibration and operation periods (calibration PAR/REM). The term $d_{0}$ in Eq. (6) used for DS 3 is a piecewise linear function of 60-day intervals while it is a constant for DS 2. The features of these data sets are summarised in Table 4.

In addition to individual sensor values, the mean $\mathrm{SU}$ value of the redundant $\mathrm{NO}_{2}$ and $\mathrm{O}_{3}$ sensors was also computed for DS 1 to DS 3 (exceptions are that SU004 and SU005 rely only on one $\mathrm{O}_{3}$ sensor, SU002 relies only on two $\mathrm{NO}_{2}$ sensors; compare Figs. 6 and S7 in the Supplement). Discussions in Sect. 5.3, 5.4 and 5.6 refer to this mean SU value and not to individual sensors. The application of a sensor model to the raw measurements of an individual sensor can lead to negative concentrations and accordingly to negative $1 \mathrm{~min}$ SU mean values. Negative 1 min SU mean values were set to zero for the computation of average SU values for longer time periods (i.e. $30 \mathrm{~min}$ and 14-day values corresponding to the measuring intervals of the diffusion tubes).

In the following, the term "measurements" in relation to SUs refers throughout to processed values from DS 1 to DS 3. Results of the analyses were presented referring to the IDs of the SUs or the locations where the SUs were operated. Calibration history, time of operation and construction details are related to the SU ID, while encountered meteorological conditions, pollutant levels and the link of the SU measurements to measurements from AQM sites are related to the location.

\subsection{Agreement of sensor measurements}

Properly working sensors within the same SU are expected to provide comparable signals. Therefore, the measurements of the redundant $\mathrm{O}_{3}$ and $\mathrm{NO}_{2}$ sensors were compared by means of 7-day rolling R2, RMSE and absolute differences between the mean values. The analysis is twofold and based on $30 \mathrm{~min}$ measurements being part of the data sets DS 1 and DS 3 (a basic linear model and an advanced model that is also time dependent for $\mathrm{NO}_{2}$ sensors; see Table 4 for details). Measurements of DS 1 can virtually be considered raw data. Figure 6 depicts the results for the $\mathrm{NO}_{2}$ sensors. This figure reveals that, in general, the three $\mathrm{NO}_{2}$ sensors integrated in a SU are rather coherent over time by means of R2 for DS 1 and DS 3. The figure related to DS 1 shows that performing only an initial sensor calibration may result in a higher RMSE and a larger difference of the mean values. These two metrics are considerably smaller for DS 3 due to time-dependent parameters in the sensor model.

$\mathrm{R} 2$ values of neighbouring $\mathrm{O}_{3}$ sensors are high on average for DS 1 and DS 3 despite the decreased sensitivity over time (see Fig. S7 in the Supplement). This means that, indeed, the decreasing sensitivity of the $\mathrm{O}_{3}$ sensors is probably a consequence of the encountered environment conditions (Fig. 5). 

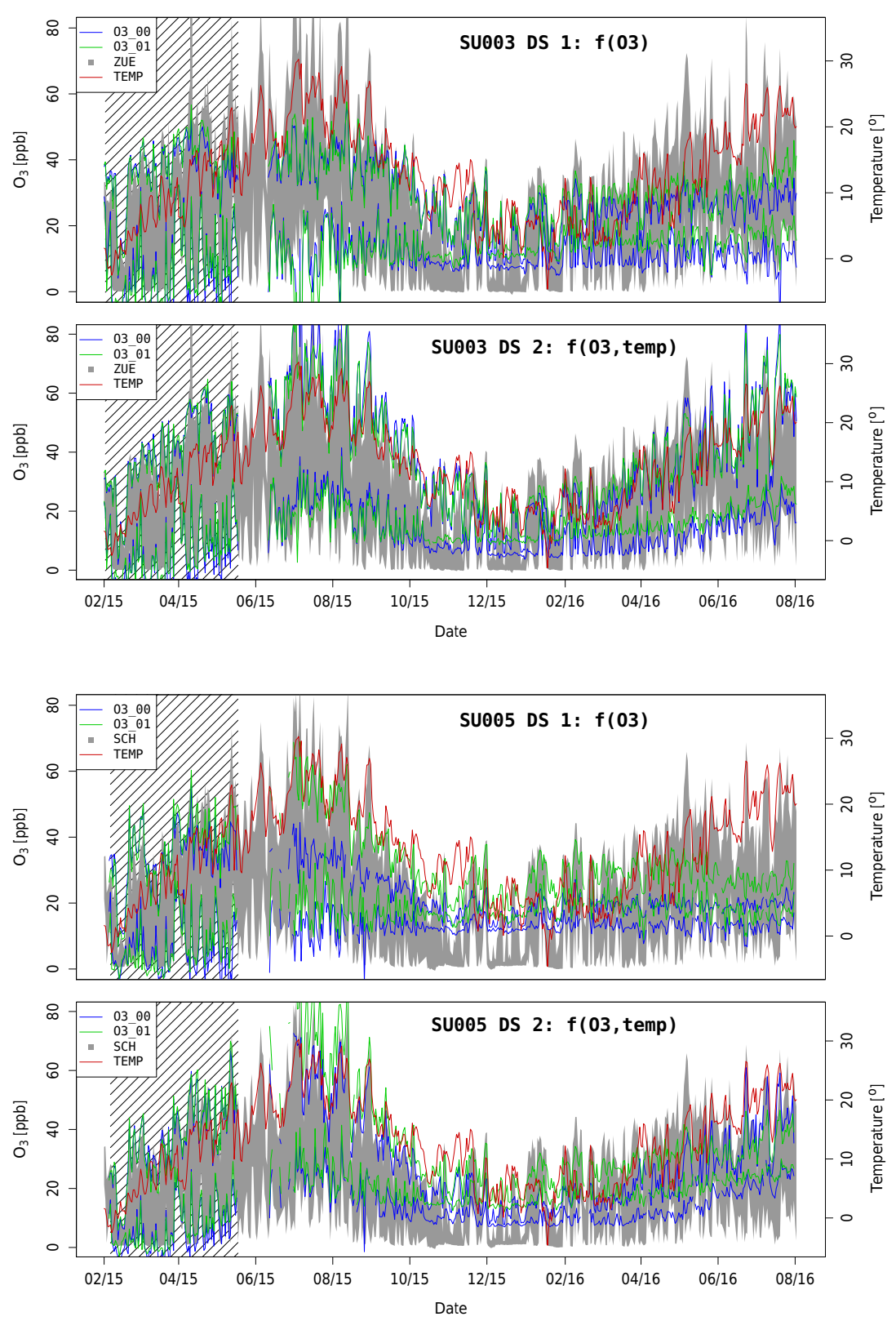

Figure 5. Daily range of 30 min mean $\mathrm{O}_{3}$ concentrations indicated by the two sensors $\mathrm{O} 3$ _00 and O3_01 integrated in the SUs 003 and 005 . It is depicted by two lines representing the daily maximum and minimum (DS 1: basic linear model; DS 2: advanced model based on Eq. (5) including temperature as a parameter; see Table 4 for details). The grey band depicts the same value for the AQM site where the sensor unit was located for calibration. This AQM site is also comparable with the location where the SU was operated within the sensor network with respect to the pollutant situation. The time period in which the sensors were calibrated at the AQM site is depicted by a shaded area (calibration PAR). Temperature is the daily mean value at AQM site ZUE.

\subsection{Comparison of fortnightly $\mathrm{NO}_{2}$ concentrations from the SUs and from diffusion tubes}

The $\mathrm{NO}_{2}$ sensor measurements were compared with fortnightly $\mathrm{NO}_{2}$ concentrations derived from diffusion tubes (Table 5). For this comparison, fortnightly sensor values have been calculated only when more than $96 \%$ of the 1 min mean values were available. In a few cases, the exposure time of the diffusion tubes differ from 2 weeks: four diffusion tubes were exposed for 3-4 weeks and two of them were exposed only for 1 week. The RMSE between uncorrected fortnightly $\mathrm{NO}_{2}$ diffusion tube measurements and measurements from the AQM sites amounts to $2.0 \mathrm{ppb}(N=216)$. Diffusion tube measurements are thus an independent and accurate reference for the $\mathrm{NO}_{2}$ mean values provided by the SUs. 
(a)


(b)
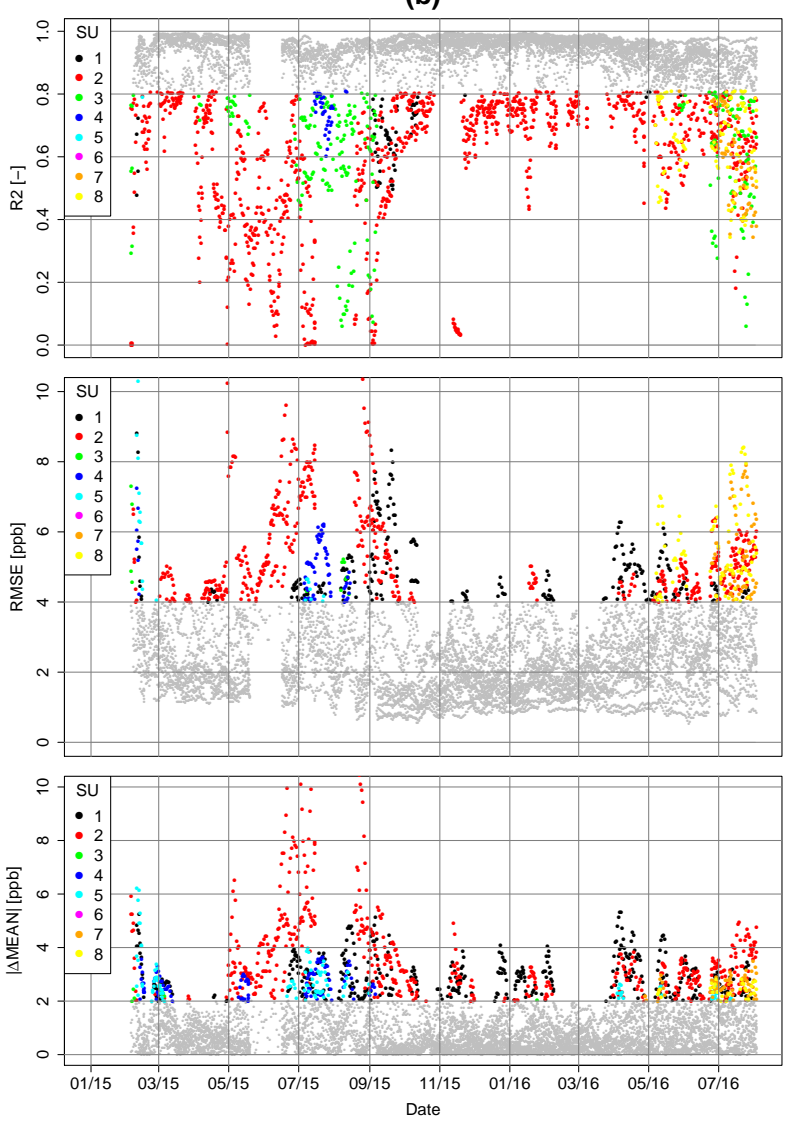

Figure 6. Comparison of measurements from the redundant $\mathrm{NO}_{2}$ sensors integrated in the SUs by means of the 7-day rolling RMSE, R2 and absolute average difference based on $30 \mathrm{~min} \mathrm{NO}_{2}$ concentrations. There are $n(n-1) / 2$ values for $n$ integrated sensors per day. Only time periods are considered when the SUs were calibrated or operated in the sensor net. The values in (a) are derived from DS 1 which is based on a linear fit only. The values in (b) are derived from DS 3 (calibration PAR/REM; based on Eq. 6). Corresponding results for the $\mathrm{O}_{3}$ sensors are included in the Supplement.

Figure 7a depicts the time series of fortnightly $\mathrm{NO}_{2}$ concentrations derived from diffusion tubes for the sensor network locations and the AQM sites. It shows the differences in pollution levels at the locations of the sensor network. $\mathrm{NO}_{2}$ concentrations in Zurich are generally higher in winter than in summer, especially for sites that are moderately impacted by traffic emissions. The differences between the SU and diffusion tube measurements are depicted in Fig. $7 \mathrm{~b}$ and $\mathrm{c}$ for DS 2 (calibration PAR) and DS 3 (calibration PAR/REM). There are considerable deviations between fortnightly mean $\mathrm{NO}_{2}$ concentrations of particular SUs derived from DS 2 and from diffusion tubes. In particular, the deviation of about $10 \mathrm{ppb}$ observed for site WIN (SU005) is remarkable. The origin of this offset is unknown but refers to the time period between calibration and deployment. It evidences the importance of performance monitoring strategies for lowcost sensors. Agreement between diffusion tube measurements and DS 3, which includes time-dependent parameters derived from information provided by AQM sites, is clearly better. However, there are still significant deviations (up to $10-15 \mathrm{ppb}$ ), in particular fortnightly periods (e.g. values of site BUE on 11 and 25 August 2016).

Replacement of diffusion tubes by low-cost sensors would be an interesting option due to the high temporal resolution of sensors. However, further improvements of the sensors and the processing procedures are required to reach the accuracy and reliability level of diffusion tube measurements.

\subsection{Linking SU measurements to measurements from AQM site ZUE}

We compared $\mathrm{NO}_{2}$ and $\mathrm{O}_{3}$ measurements at locations of the sensor network (SUs) as well as the AQM site network with measurements from AQM site ZUE by computing the concentration differences. The analysis is twofold: firstly, it takes into account all the data obtained during the operation of the sensor network. Secondly, it utilises only the data from time periods in which the concentration ranges within the respective AQM site groups (background or city) are below $5 \mathrm{ppb}$ 

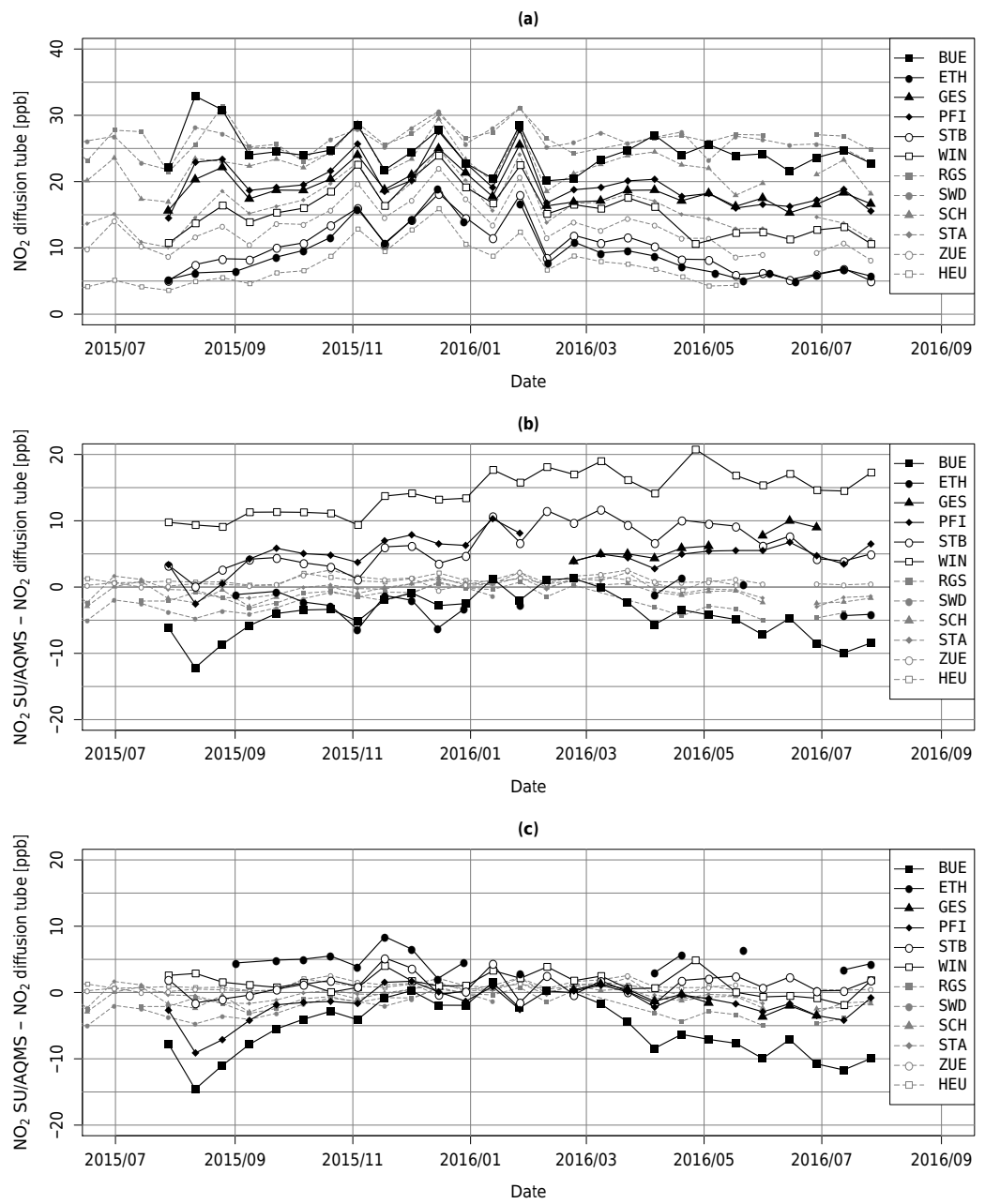

Figure 7. (a) Fortnightly $\mathrm{NO}_{2}$ diffusion tube measurements. (b, c) Differences between fortnightly $\mathrm{NO}_{2}$ mean values provided by $\mathrm{SUs}$ (DS 2 in $\mathbf{b}, \mathrm{DS} 3$ in $\mathbf{c}$ ) and by diffusion tubes.

(Fig. 8a to c). We expect similar distributions for the differences between SUs and AQM sites, which are comparable in terms of site type.

Figure 8a depicts $\mathrm{NO}_{2}$ data from DS 2 (calibration PAR) showing large offsets $(>5 \mathrm{ppb})$ between the measured and the expected mean for sites PFI and WIN in the selected time periods. Note that the AQM site SWD is not part of any AQM site group, confirming the effectiveness of this analysis approach. As expected, the fit of DS 3 (calibration PAR/REM) is clearly better because the data from the selected time periods were used for the determination of sensor model parameters (Fig. 8b). The scattering of the concentration differences for the SUs is significantly larger than for the AQM sites, pointing to a lower accuracy of the sensors.

The potential of monitoring and improving low-cost sensors based on measurements from AQM sites is illustrated in Fig. 9. This figure shows the variation of the parameter $d_{0}$ which is time dependent for $\mathrm{NO}_{2}$ sensors in DS 3. It accounts for temporal variations of the zero point offset. In addition, this figure shows the comparison of the concentration differences between fortnightly diffusion tube measurements and fortnightly means of $\mathrm{NO}_{2}$ sensor measurements of DS 2 (no time-dependent parameters) with the parameter $d_{0}$ of DS 3 . The good correspondence of these two independent values demonstrates that linking data from AQM sites and from sensors is useful. Identification of time periods when measurements at AQM sites indicate small intra-urban gradients in air pollutant levels helped to improve the quality of the sensor data. This is a basic strategy for the performance monitoring of sensors. Further, it shows that sensor measurements can even be improved based on this strategy. A remaining prerequisite is that the sensitivity of the sensor is sufficiently stable as minimum values are better constrained by linking measurements from different locations than the span.

The agreement of the $\mathrm{O}_{3}$ sensor measurements of DS 3 is rather weak but concurs with the reduction of sensitivity with advancing operation time (Fig. 8c; see also Fig. 5). 

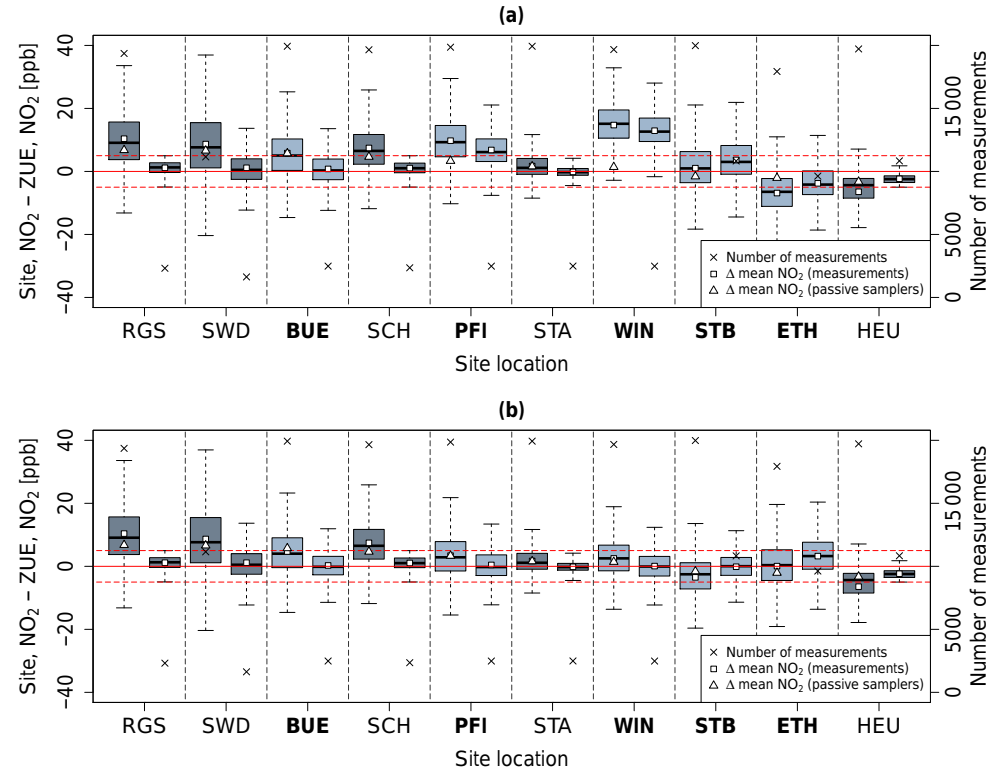

(c)



Figure 8. Analysis of the differences between $\mathrm{NO}_{2}$ and $\mathrm{O}_{3}$ measurements from the $\mathrm{SUs}$ (names of the sensor network locations in bold)/AQM sites and measurements from the AQM site ZUE. The comparison is twofold: for each site, the boxes on the left include all measurements while the boxes on the right only include the measurements when concentration ranges are below 5 ppb for the AQM site groups background and city. Measurements of DS 2 are used in (a). Measurements of DS 3 are used in (b, c). Note that the sensor network locations STB and ETH refer to the group background (HEU, ZUE) and the locations BUE, PFI, GES and WIN refer to the group city (RGS, SCH, STA, ZUE).
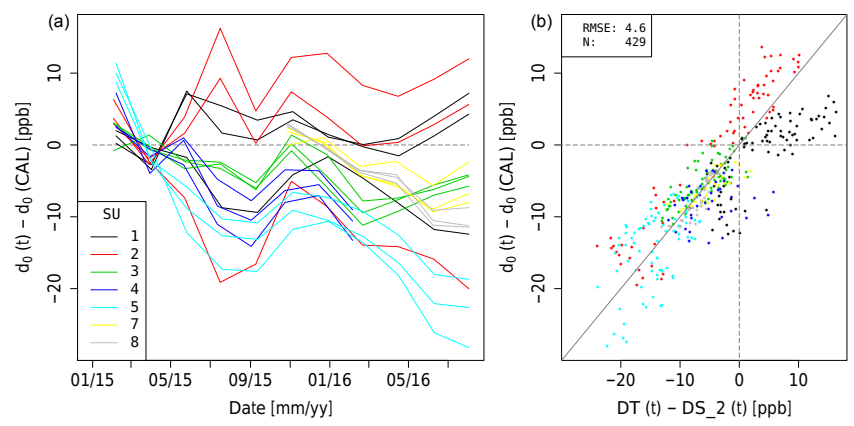

Figure 9. (a) Time series of the piecewise linear function $d_{0}$ of Eq. (6) (DS 3: calibration PAR/REM) with the average $d_{0}$ value during the initial calibration phase subtracted. (b) Comparison of the values from (a) with the difference between fortnightly $\mathrm{NO}_{2}$ concentrations from diffusion tubes (DT) and measurements from the $\mathrm{NO}_{2}$ sensors (DS 2: Eq. 6 with $d_{0}=$ const, calibration PAR). The depicted solid line shows the $1: 1$ ratio.

\subsection{Recalibration of SUs}

At two locations of the sensor network the SU were replaced after 6 months of operation: at locations PFI (SU004 by SU007) and GES (SU006 by SU008; see Table 3 for dates). SU004 and SU006 have run in Zurich for about 1 year in total at this time. Directly after their replacement they were operated at the AQM site $\mathrm{SCH}$ for 1 month more. These data were used to analyse the sensor performance after 1 year of operation by analysing the fit between the measurements of the calibrated sensors (DS 2: initial calibration) and the measurements from the AQM site.

The agreement of the four $\mathrm{O}_{3}$ sensors with the measurements from the AQM site was poor in terms of RMSE (Fig. 10; compare also Fig. 5). However, the correlation between measurements from the $\mathrm{O}_{3}$ sensors and the reference instrument was still between 0.59 and 0.91 .

The RMSE of the $\mathrm{NO}_{2}$ sensors amounted to 8.0-11.7 and 6.1-9.2 ppb for SU004 (NO2-B42F) and SU006 (NO2-B4, 

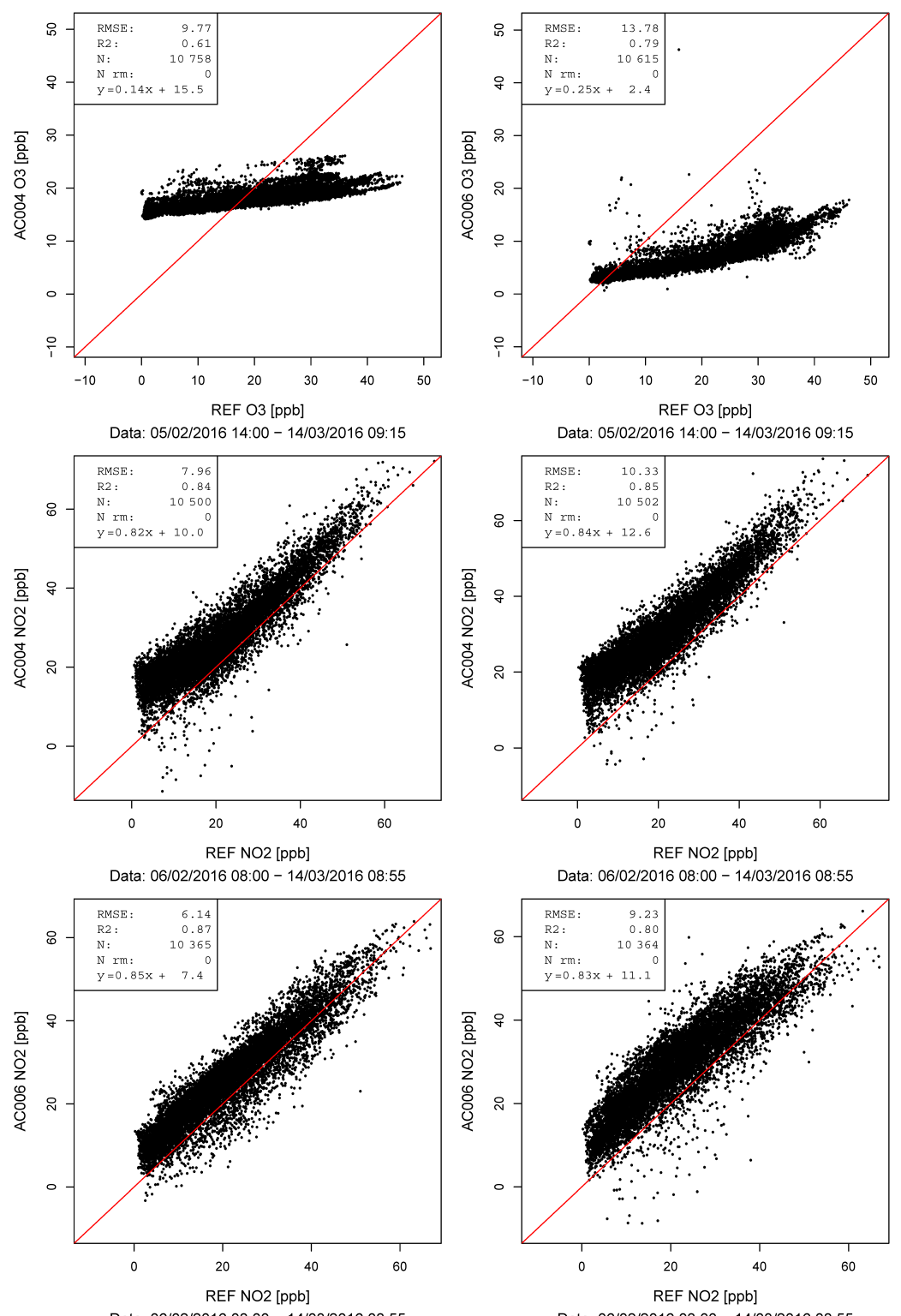

Figure 10. Comparison of the measurements from sensors integrated in SU004 and SU006 (DS 2) to measurements from the AQM site SCH during the second calibration in the period February to March 2016. Top row: $\mathrm{O}_{3}$ sensor no. 0 of SU004 and SU006. Middle row: $\mathrm{NO}_{2}$ B42F sensors no. 0 and 1 of SU004. Bottom row: $\mathrm{NO}_{2}$ B4 sensors no. 0 and 1 of SU006. The selected sensors are representative.

applied $\mathrm{O}_{3}$ correction based on measurements from the $\mathrm{O}_{3}$ instrument of site $\mathrm{SCH}$ ). Correlation was above 0.89 for all the sensors. Figure 10 shows that the sensitivity of the three examined NO2-B42F and NO2-B4 sensors remained rather stable over the 1-year period. The linear dependency between sensor and reference measurements can essentially be described by an offset of several ppb and a slope of $\sim 0.8-0.9$. The offsets agree very closely with the $d_{0}(t)$-terms included in the sensor model described by Eq. (6) on which $\mathrm{NO}_{2}$ values of DS 3 are based (Fig. 9). The analysis gives clear evidence for the necessity of ongoing performance analysis strategies when using such sensors for air quality monitoring.

\subsection{Comparison of diurnal $\mathrm{NO}_{2}$ variations}

The locations of the sensor network were selected in order to have a corresponding AQM site in terms of the pollution situation. This facilitates the comparison of patterns of diurnal variation in pollutant concentration at different locations. Figure 11 separately depicts the diurnal variation for working days and weekends/public holidays for the two corresponding AQM and sensor network site pairs for the period May to July 2016. At this time the SUs have been operated at these locations for 1 year. The patterns of diurnal variations in $\mathrm{NO}_{2}$ are as expected given the typical diurnal cycle of the traffic 

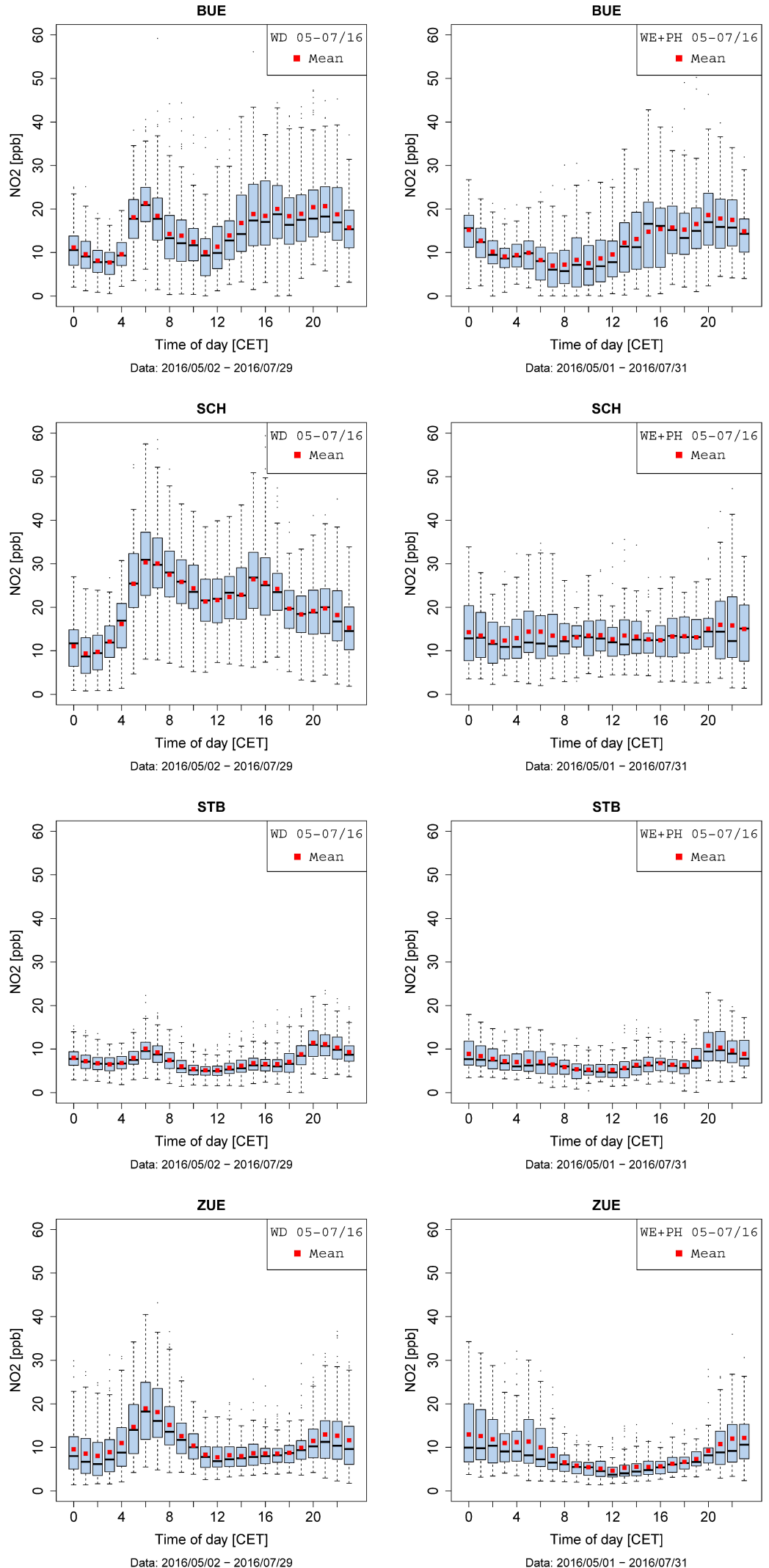

Figure 11. Comparison of the diurnal variation of $\mathrm{NO}_{2}$ concentration at two AQM sites ( $\mathrm{SCH}$ and ZUE) and at two sensor network locations (BUE and STB, data from DS 3). The left-hand figures depict data from working days (WD), the right-hand figures data from weekends and public holidays $(\mathrm{WE}+\mathrm{PH})$. Sites RGS and BUE are roadside locations, sites STB and ZUE are background locations. 
Table 5. Comparison of the $\mathrm{NO}_{2}$ concentrations provided by the SU with the diffusion tube concentrations for each site of the sensor network. The row denoted by AQM summarises the comparison between measurements from instruments of AQM sites and diffusion tube measurements. Data set refers to the sensor data processing strategy outlined in Table 4. RMSE, $r$ and $N$ denote the root mean square error, the Pearson correlation coefficient and the number of samples, respectively.

\begin{tabular}{llrrr}
\hline Data set & site & $\begin{array}{r}\text { RMSE } \\
\text { [ppb] }\end{array}$ & $r$ & $N$ \\
\hline DS 2 & BUE & 5.4 & 0.37 & 27 \\
DS 3 & BUE & 6.9 & 0.26 & 27 \\
DS 2 & ETH & 3.2 & 0.86 & 15 \\
DS 3 & ETH & 5.0 & 0.93 & 15 \\
DS 2 & GES & 6.6 & -0.20 & 9 \\
DS 3 & GES & 2.0 & 0.65 & 9 \\
DS 2 & PFI & 5.6 & 0.80 & 26 \\
DS 3 & PFI & 3.0 & 0.78 & 26 \\
DS 2 & STB & 6.9 & 0.74 & 27 \\
DS 3 & STB & 2.0 & 0.90 & 27 \\
DS 2 & WIN & 14.6 & 0.68 & 26 \\
DS 3 & WIN & 2.1 & 0.92 & 26 \\
- & AQM & 2.0 & 0.97 & 216 \\
- & AQM & 2.0 & 0.97 & 216 \\
\hline
\end{tabular}

activity and boundary layer stability. Obviously, the accuracy of a single $30 \mathrm{~min} \mathrm{NO}_{2}$ concentration provided by the sensors cannot be quantified in this configuration.

\section{Conclusions}

We find that $\mathrm{O}_{3}$ and $\mathrm{NO}_{2}$ low-cost gas sensors can provide concentration measurements with an accuracy of a few ppb (3-8 ppb) in the first 1-3 months of operation. Comparisons with diffusion tube measurements and measurements from AQM sites revealed that this accuracy could not be maintained during the entire 1-year network deployment due to the changing response behaviour of the sensors. Several issues were encountered that were related to the employed sensors that effect a temporary ( $\sim$ hours) or persistent decrease of sensor accuracy. Hence, the application of performance monitoring strategies is a prerequisite of operating low-cost sensors with such properties in order to be able to assess the quality of the data.

All the sensors of the employed types require individual calibration. Sensor calibration next to reference sites is timeconsuming and requires infrastructure. Moreover, the quality of the compiled calibration data set for the model parameter estimation depends on the prevalent ambient conditions (i.e. encountered pollutant concentrations, meteorology).

The signal of the employed $\mathrm{NO}_{2}$ sensors is heavily impacted by changes in relative humidity. This effect can be reduced to a certain degree by the application of a correc- tion function but still limits the achievable accuracy of the sensors. This issue points to the necessity of an improved mathematical description of the sensor based on its working principle in order to describe sensor behaviour in more detail. More sophisticated sensor models may facilitate calibration as its parameters can possibly be constrained with less effort than is required when applying regression models.

$\mathrm{NO}_{2}$ and $\mathrm{O}_{3}$ concentration predictions can be derived on the level of a few ppb at specific time periods for many locations in Zurich using the data from the AQM site network which covers a wide range of different pollutant situations. This feature can be a substantial factor for an effective monitoring of the sensor performance in low-cost sensor networks. Moreover, such data can be used for the remote correction of sensors. In our study this procedure was shown to improve the results of $\mathrm{NO}_{2}$ sensors.

Enhanced performance is required for future low-cost sensors but the extent of achievable improvements is open. Thorough sensor testing, procedures adequate for the designated application, as well as efficient performance monitoring strategies demonstrated in this study, will remain important features in sensor-based ambient air quality monitoring.

Data availability. The data used in this study can be obtained from the authors upon request.

\section{The Supplement related to this article is available online} at https://doi.org/10.5194/amt-10-3783-2017-supplement.

Competing interests. Author Jonas Meyer is the CTO of DecentLab, the manufacturer of the sensor units. The sensor units have jointly been developed by Decentlab and Empa. Jonas Meyer was solely involved in development and manufacturing of the sensor units and in the transmission of the raw sensor data into the database hosted by DecentLab and was not involved in sensor deployment or in data analysis. The authors declare that they have no other competing interests.

Acknowledgements. We thank Jürg Brunner, Markus Scheller, Noel Rederlechner and Barbara Siegfried from the Environment and Health Protection Department of the City of Zurich for providing measurements from AQM sites, for their contribution to and performance of the diffusion tube measurements and for their support related to sensor calibrations. Moreover, we acknowledge the support of Michael Meindl from ETH Zurich during the diffusion tube campaign. Peter Graf and Yannick Stöeferle, Empa, supported the sensor testing in our laboratory. The project was financially supported by the Swiss State Secretariat for Education, Research and Innovation (SERI) and the Swiss Federal Office for the Environment (FOEN). 
Edited by: Francis Pope

Reviewed by: three anonymous referees

\section{References}

Alphasense Ltd.: available at: http://www.alphasense.com, last access: 28 April 2016.

Brunner, J. and Scheller, M.: Luftbilanz Stadt Zürich (Air quality report of the city of Zurich)., Tech. rep., no. 20140124, available at: https://www.stadt-zuerich.ch/content/dam/stzh/ gud/Deutsch/UGZ/Gesundheitsschutz/Schadstoffe_Laerm_ Strahlen/Aussenraum/Luft/\%3EDokumenteundPublikationen/ Luftbilanz/ugz_umw_la_20140124_luftbilanz_2012.pdf (last access: 12 September 2017), 2014 (in German).

Jiao, W., Hagler, G., Williams, R., Sharpe, R., Brown, R., Garver, D., Judge, R., Caudill, M., Rickard, J., Davis, M., Weinstock, L., Zimmer-Dauphinee, S., and Buckley, K.: Community Air Sensor Network (CAIRSENSE) project: evaluation of low-cost sensor performance in a suburban environment in the southeastern United States, Atmos. Meas. Tech., 9, 5281-5292, https://doi.org/10.5194/amt-9-5281-2016, 2016.

Li, J., Faltings, B., Saukh, O., Hasenfratz, D., and Beutel, J.: Sensing the Air We Breathe - The OpenSense Zurich Dataset, Proceedings of the Twenty-Sixth AAAI Conference on Artificial Intelligence, 2012.

Lin, C., Gillespie, J., Schuder, M., Duberstein, W., Beverland, I., and Heal, M.: Evaluation and calibration of Aeroqual series 500 portable gas sensors for accurate measurement of ambient ozone and nitrogen dioxide, Atmos. Environ., 100, 111-116, https://doi.org/10.1016/j.atmosenv.2014.11.002, 2015.

Mead, M. I., Popoola, O. A. M., Stewart, G. B., Landshoff, P., Calleja, M., Hayes, M., Baldovi, J. J., McLeod, M. W., Hodgson, T. F., Dicks, J., Lewis, A., Cohen, J., Baron, R., Saffell, J. R., and Jones, R. L.: The use of electrochemical sensors for monitoring urban air quality in lowcost, high-density networks, Atmos. Environ., 70, 186-203, https://doi.org/10.1016/j.atmosenv.2012.11.060, 2013.
Miskell, G., Salmond, J., Alavi-Shoshtari, M., Bart, M., Ainslie, B., Grange, S., McKendry, I. G., Henshaw, G. S., and Williams, D. E.: Data Verification Tools for Minimizing Management Costs of Dense Air-Quality Monitoring Networks, Environ. Sci. Technol., 50, 835-846, https://doi.org/10.1021/acs.est.5b04421, 2016.

Palmes, E. D., Gunnison, A., DiMattio, J., and Tomczyk, C.: Personal sampler for nitrogen dioxide, Am. Ind. Hyg. Assoc. J., 37, 570-577, https://doi.org/10.1080/0002889768507522, 1976.

Piedrahita, R., Xiang, Y., Masson, N., Ortega, J., Collier, A., Jiang, Y., Li, K., Dick, R. P., Lv, Q., Hannigan, M., and Shang, L.: The next generation of low-cost personal air quality sensors for quantitative exposure monitoring, Atmos. Meas. Tech., 7, 3325-3336, https://doi.org/10.5194/amt-7-3325-2014, 2014.

R Core Team: R: A Language and Environment for Statistical Computing, R Foundation for Statistical Computing, Vienna, Austria, available at: https://www.R-project.org/ (last access: 12 September 2017), 2015.

Snyder, E. G., Watkins, T. H., Solomon, P. A., Thoma, E. D., Williams, R. W., Hagler, G. S. W., Shelow, D., Hindin, D. A., Kilaru, V. J., and Preuss, P. W.: The Changing Paradigm of Air Pollution Monitoring, Environ. Sci. Technol., 47, 11369-11377, https://doi.org/10.1021/es4022602, 2013.

Spinelle, L., Gerbole, M., Villani, M. G., Aleixandre, M., and Bonavitacolada, F.: Field calibration of a cluster of low-cost available sensors for airquality monitoring. Part A: Ozone and nitrogen dioxide, Sensor. Actuat. B-Chem., 215, 249-257, https://doi.org/10.1016/j.snb.2015.03.031, 2015.

Stetter, J. R. and Li, J.: Amperometric Gas SensorsA Review, Chem. Rev., 108, 352-366, https://doi.org/10.1021/cr0681039, 2008.

Williams, D. E., Henshaw, G. S., Bart, M., Laing, G., Wagner, J., Naisbitt, S., and Salmond, J. A.: Validation of low-cost ozone measurement instruments suitable for use in an air-quality monitoring network, Measurement Science and Technology, 24, 065803, https://doi.org/10.1088/0957-0233/24/6/065803, 2013. 